\section{Commentary: Will the next improvement in the care of single ventricle patients come from focusing on patient selection for the cavopulmonary shunt?}

\author{
Heather L. Bartlett, MD, and \\ Petros V. Anagnostopoulos, MD, MBA
}

To paraphrase Winston Churchill, although the cavopulmonary shunt (CPS) has issues, it is the best option we have. In 1977, Choussat and colleagues delineated the renowned 10 selection criteria for the Fontan procedure. These guidelines have been revised over the years, with improvements in the assessment and management of patients with single ventricle physiology. ${ }^{1}$ More recently, advances have concentrated on early infant care before the CPS. ${ }^{2}$ The period between CPS and Fontan has been relatively overlooked, however. Despite the beneficial transition to a more stable physiology, the CPS is not risk-free. In this issue of the Jour$n a l$, Callahan and colleagues ${ }^{3}$ address this interstage period and analyze risk factors associated with death/transplantation versus Fontan completion. To minimize confounding factors, they studied patients with tricuspid atresia, a lesion considered to have the most favorable anatomy and outcomes among single ventricle diseases.

Even with the advantageous anatomy of tricuspid atresia, $5 \%$ of patients died or underwent transplantation after CPS. Unsurprisingly, moderate or greater mitral valve regurgitation was a risk factor for poor outcome, in line with previous findings. ${ }^{4}$ The study also addressed the controversial issue

\footnotetext{
From the Congenital Heart Program, The American Family Children's Hospital, The University of Wisconsin Hospital and Clinics, Madison, Wis.

Disclosures: The authors reported no conflicts of interest.

The Journal policy requires editors and reviewers to disclose conflicts of interest and to decline handling or reviewing manuscripts for which they may have a conflict of interest. The editors and reviewers of this article have no conflicts of interest.

Received for publication April 14, 2021; revisions received April 14, 2021; accepted for publication April 15, 2021; available ahead of print April 20, 2021.

Address for reprints: Petros V. Anagnostopoulos, MD, MBA, Pediatric Cardiothoracic Surgery, American Family Children's Hospital, H4/358 Clinical Sciences Center, 600 Highland Ave, Madison, WI 53792 (E-mail: petros@surgery.wisc. edu).

J Thorac Cardiovasc Surg 2022;163:410-1

$0022-5223 / \$ 36.00$

Copyright (c) 2021 by The American Association for Thoracic Surgery

http://dx.doi.org/10.1016/j.jtcvs.2021.04.040
}

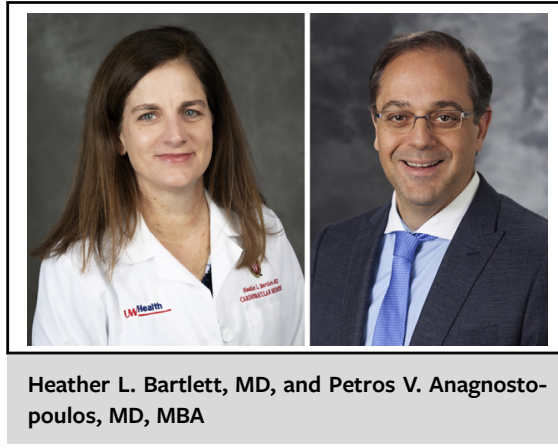

CENTRAL MESSAGE

The next steps in the improvement of outcomes in single ventricle patients may come from improved patient selection for the cavopulmonary shunt.

of antegrade pulmonary blood flow, the risks and benefits of which have been debated in the literature for more than 2 decades. Some scholars have advocated leaving antegrade flow to the pulmonary arteries to improve pulmonary artery growth and limit arteriovenous malformations. The technique is also used to offset for marginal preoperative anatomy and physiology. Whether the increased risk of death or transplantation with antegrade pulmonary blood flow reflects the preoperative anatomy or the postoperative physiology, the findings of Callahan and colleagues support those of a recent study by Baek and colleagues, ${ }^{5}$ which also demonstrated a survival disadvantage.

Technical factors also influence results. Postoperative superior vena cava intervention was associated with death or transplantation. Early identification and management of residual lesions has become a tenet for improving outcomes. ${ }^{6}$ Recognizing issues with the CPS can be challenging with traditional intraoperative transesophageal echocardiography. ${ }^{7}$ Regardless, the conclusions reinforce that intraoperative assessment of the cavopulmonary circuit to identify and immediately address residual lesions can improve outcomes.

Is it time to start thinking about criteria similar to Choussat's Fontan commandments for the CPS? We all know that some CPS patients do not do well. Improvements in surgical outcomes are often a result of refinements in patient selection. Identifying high-risk patients will aid preoperative planning and development of alternate or staged care strategies. The field has developed 
beneficial detailed approaches to the care of single ventricle patients. The next steps for improvement may well come from the second interstage.

\section{References}

1. Stern HJ. Fontan "ten commandments" revisited and revised. Pediatr Cardiol. 2010;31:1131-4.

2. Ghanayem NS, Hoffman GM, Mussatto KA, Cava JR, Frommelt PC, Rudd NA, et al. Home surveillance program prevents interstage mortality after the Norwood procedure. J Thorac Cardiovasc Surg. 2003;126:1367-77.

3. Callahan CP, Jegatheeswaran A, Barron DJ, Husain SA, Eghtesady P, Welke KF, et al. Factors associated with mortality or transplantation versus Fontan completion after cavopulmonary shunt for patients with tricuspid atresia. J Thorac Cardiovasc Surg. 2022;163:399-409.e6
4. Kulkarni A, Patel N, Singh TP, Mossialos E, Mehra MR. Risk factors for death or heart transplantation in single-ventricle physiology (tricuspid atresia, pulmonary atresia, and heterotaxy): a systematic review and meta-analysis. J Heart Lung Transplant. 2019;38:739-47.

5. Baek JS, Park CS, Choi ES, Yun TJ, Kwon BS, Yu JJ, et al. The impact of additional antegrade pulmonary blood flow at bidirectional Glenn shunt on longterm outcomes. J Thorac Cardiovasc Surg. 2021;162:1346-55.e4.

6. Nathan M, Gauvreau K, Liu H, Pigula FA, Mayer JE, Colan SD, et al. Outcomes differ in patients who undergo immediate intraoperative revision versus patients with delayed postoperative revision of residual lesions in congenital heart operations. J Thorac Cardiovasc Surg. 2014;148:2540-6.e1-e5.

7. Lamers L, Jimenez EE, Allen C, Hoyme D, Lushaj EB, Anagnostopoulos PV. Intraoperative completion angiogram may be superior to transesophageal echocardiogram for detection of pulmonary artery residual lesions in congenital surgery. Pediatr Cardiol. 2018;39:884-91.
See Article page 399.

\section{Commentary: There are no facts, only interpretations}

\author{
Bahaaldin Alsoufi, MD
}

In the current issue of the Journal, Callahan and colleagues ${ }^{1}$ report their study of infants born with tricuspid atresia and normally related great arteries from the Congenital Heart Surgeons Society (CHSS) cohort. They focused on outcomes following cavopulmonary shunt (CPS) and examined factors associated with Fontan completion, death, or transplantation following CPS. They found that by 5 years after CPS, $5 \%$ of the patients died or underwent transplantation and $91 \%$ transitioned to Fontan. They determined that preoperative moderate or greater mitral regurgitation, concomitant mitral repair, a pulmonary artery band (PAB) at CPS, and postoperative superior vena cava interventions, including CPS takedown, were associated with death or transplantation. In addition, a PAB at CPS and prenatal diagnosis were associated with decreased Fontan completion. They concluded that several risk factors contributed

\footnotetext{
From the Department of Cardiovascular and Thoracic Surgery, University of Louisville School of Medicine, Norton Children's Hospital, Louisville, Ky.

Disclosures: The author reported no conflicts of interest.

The Journal policy requires editors and reviewers to disclose conflicts of interest and to decline handling or reviewing manuscripts for which they may have a conflict of interest. The editors and reviewers of this article have no conflicts of interest.

Received for publication April 25, 2021; revisions received April 25, 2021; accepted for publication April 26, 2021; available ahead of print May 2, 2021.

Address for reprints: Bahaaldin Alsoufi, MD, Department of Cardiovascular and Thoracic Surgery, University of Louisville School of Medicine, Norton Children's Hospital, 201 Abraham Flexner Way, Suite 1200, Louisville, KY 40202 (E-mail: balsoufi@hotmail.com).

J Thorac Cardiovasc Surg 2022;163:411-2

$0022-5223 / \$ 36.00$

Copyright (c) 2021 by The American Association for Thoracic Surgery

http://dx.doi.org/10.1016/j.jtcvs.2021.04.079
}

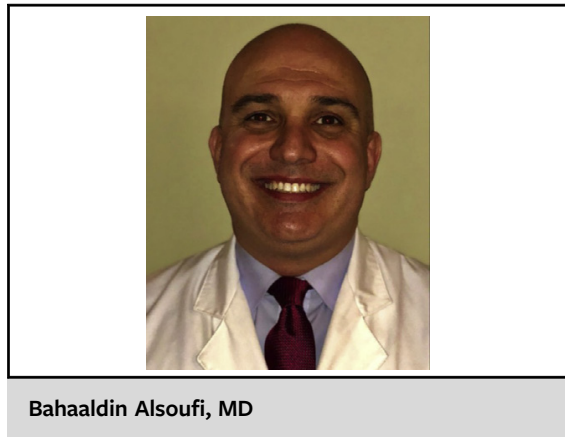

CENTRAL MESSAGE

Causality between risk factors and outcomes might be difficult to explain, thus limiting our ability to recommend practice changes that would improve results.

to the mortality following CPS, and that a PAB at CPS contributed to both death and lack of progression toward Fontan. ${ }^{1}$

The CHSS has accumulated a large number of patients who were enrolled in numerous study cohorts, including patients with tricuspid atresia. Their sophisticated analyses of these cohorts have contributed to our understanding and subsequently have helped shape the management strategies for various complex congenital heart defects. Advantages of these CHSS studies include the large cohort, the comprehensive dataset, and the long follow-up. Disadvantages include the differing practice patterns among centers and the common lack of clinical information that often 